\title{
Wired to the World
}

Ralph Scott

\section{iTunes University}

iTunes University sounds like an invention of Disney Studios that provides cartoon characters with a broad-based education. Instead iTunes started out as a venture by Apple into higher education content management. It is a free service that "allows instructors, administrators and affiliates ... to manage, distribute, and control access to educational audio and video content for students within a college or university using Apple's iTunes Store infrastructure.” A number of academic institutions have decided not only to use this system to provide their students with courses, but also to open the door to these courses to alumni - and in some cases the general public - for free. Apple has been so successful that it has expanded the service beyond the university venue and is now supplying additional material such as U.S. Supreme Court oral arguments, and radio broadcast recordings from the civil rights movement. Major university players in the iTunes network include such institutions as Purdue, Duke, Yale, Harvard, Berkeley, and Stanford. Recently public broadcasting stations such as KQED and museums such as the Museum of Modern Art in New York have joined iTunes in offering programs to watch or listen to.

Promoted as the "university that never sleeps" iTunes University allows lectures, presentations, laboratory experiments, and even historic movies and songs to be uploaded to their systems. Students and faculty familiar with the ubiquitous iPods will find the iTunes University easy to use. Faculty can post assignments and lectures; then students can download the segments to their computers or iPods for review whenever and as often as they choose. The system was created about a year ago and has proven quite popular with students. A good place to get started looking over the course offerings is at www.apple.com/education/ itunesu where you can find a link to the iTunes Store. If you already have iTunes on your computer, when you launch the application you will see the new iTunes University offering listed at the end of the iTunes Store sidebar. A number of the courses are free, but some are sold to students through the online store system.

Apple offers a number of guides and tip sheets for faculty and system administrators at www.apple.com/support/ itunes_u/ Faculty guides cover "Creating your iTunes Site," "Promoting your iTunes U Site," "Creating Content for iPod + iTunes," a user's guide to the system, and a wonderful pdf file called "Uploading Content? Get the iTunes U Copyright Overview." Administrator files include tips for capture, creation, digitization, and uploading of course content. There is also a file dealing with the authentication protocols for those who want to charge students through the store purchase or a local proxy system. There is also a FAQ to look up problems that others have had and an iTunes Discussion forum to chat with other iTunes users. A number of universities have found iTunes a great way to deliver continuing education seminars as well as a way to stay in touch via lectures podcasted to alumni. Librarians will find this technique a great way to deliver bibliographic and other instruction to students 24 hours a day, seven days a week. The beauty of this system is that while students are working on assignments in the library they can review the lecture presented by the librarian on their iPods or computers to refresh their memories.

The Wired to the World editor looked at a number of iTunes University offerings. For example, podcasts are available from the Bowdoin University Peary-MacMillan Arctic Museum about early motion picture film footage of natives on Crocker land in the early twentieth century in North West Greenland. Concordia Seminary has both video and audio podcasts of the fundamentals of New Testament Greek course taught by Professor James L. Voeltz. Purdue University has begun to podcast over 50 different course lectures for students to review after the initial lecture is over (http://boilercast.itap.purdue.edu:1013/Boilercast). Texas A\&M has a number of free offerings in its "Integrative Center for Homeland Security." "Just a Minute for Homeland Security" is a weekly podcast of current issues (110 weeks of programs are available for downloading). "Homeland Security In and Out" is "a weekly one hour public radio program that features interviews with key leaders at the federal, state and local levels of government, plus senior leaders in the private sector, academic community, and national news media.” Hopefully other universities will add similar types of rich and varied content to their website offerings for downloading through iTunes University. Librarians will find this iPod technology an innovative way to deliver information about their libraries and services. 